\title{
The Effect of ANKK1 Taq1A Polymorphism on Cognition in Recent-Onset Psychosis: A Controlled Study
}

\author{
Vanessa Sanchez Gistau $^{1,+}$, Lourdes Martorell ${ }^{1}$, Angel Cabezas ${ }^{1}$, Sara Arranz ${ }^{1}$, Lorena \\ Moreno ${ }^{1}$, Rosa Marine ${ }^{1}$, Javier Labad ${ }^{2}$, Elisabet Vilella ${ }^{1}$
}

\begin{abstract}
Background

The T allele of rs1800497 SNP of ANKK1 gene has been linked to a poorer performance on prefrontal cognitive processes. There is the lack of studies investigating the effect of this variant on cognition in schizophrenia. Our main aim therefore was to investigate its impact on cognition in a sample of subjects with a recent diagnosis of psychosis

Methods

We included 128 patients with recent -onset psychosis (ROP) and 70 healthy controls (HC) with both complete neuropsychological assessment by MATRICS Consensus Cognitive Battery (MCCB) and blood specimen drawn for DNA analysis. Genotypes were grouped following an additive model. We explored main effects of disease (ROP and $\mathrm{HC}$ ) and genetics $\left(\mathrm{T}^{+}\right.$and $\left.\mathrm{T}^{-}\right)$and their interaction term on cognition.

Results

Two'way ANOVAs showed a significant genetic and disease interaction effect in WMS -SS (non verbal working memory) $(F=10.32, p=0.002$, partial eta squared $=0.05)$ and on $M C C B$ total score $(F=5.02, p=0.02$, partial eta squared $=0.03$ ). When sample was stratified by allele status, $\mathrm{ROP}^{-} \mathrm{T}^{+}$performed poorly than $\mathrm{HC}^{-} \mathrm{T}^{+}$in WMS-SS, while that difference was not found among $\mathrm{T}^{-}$. Within ROP, T carriers presented a worse cognitive profile than non carriers but within $\mathrm{HC}$, cognitive profile did not differ as a function of allele status. When adjusting for clinical confounders both WMS $\mathrm{SS}(\mathrm{F}=9.53, \mathrm{p}=0.003$, partial eta squared $=0.09$ ) and total MCBB scores $\left(F=7.09, p=0.009\right.$, partial eta squared $=0.08$ ) continued to be lower in $R^{2 O P}{ }^{-}{ }^{+}$compared with ROP $^{-} T^{-}$.

Conclusion

This is the first study to report an association of the vulnerability allele of Taq1 A with cognitive impairment in psychosis assessed by a standardized instrument as the MCCB battery. Our study therefore, provides preliminary evidence for the potential role of the $A N N K 1$ gene in modulating cognitive performance in psychosis.
\end{abstract}

\section{Keywords}

Cognition, $A N N K 1$, Taq1A, Schizophrenia, Working Memory, MCCB Battery, Executive Function

\section{Introduction}

The dopaminergic neurotransmitter system (DAS) has been implicated in the etiopathogenesis of schizophrenia since antipsychotics were found to reduce psychotic symptoms by blocking D2/D3 dopamine receptors [1].Findings from both animal [2] and human in vivo and postmortem studies [3-4] have provided further evidence for structural and functional abnormalities in the DAS in

${ }^{1}$ Hospital Universitari Institut Pere Mata of Reus, IIPSV, Universitat Rovira i Virgili, CIBERSAM Spain

${ }^{2}$ Department of Mental Health, Parc Taulí Hospital Universitari, Sabadell, Universitat Autonoma, I3PT, CIBERSAM Spain

${ }^{\dagger}$ Author for Correspondence: Dr. Vanessa Sanchez-Gistau, Early Intervention Program, Hospital Universitari, Institut Pere Mata of Reus. Institut Pere Mata road, 6־10 43202, Reus, Spain, Tel/fax: +34977338565; email: sanchezv@peremata.com 
schizophrenia. Since its first description, it is an ongoing reformulation of the dopamine hypothesis of schizophrenia [5]. The genes involved in DAS pathways therefore, are a major focus of attention [6].

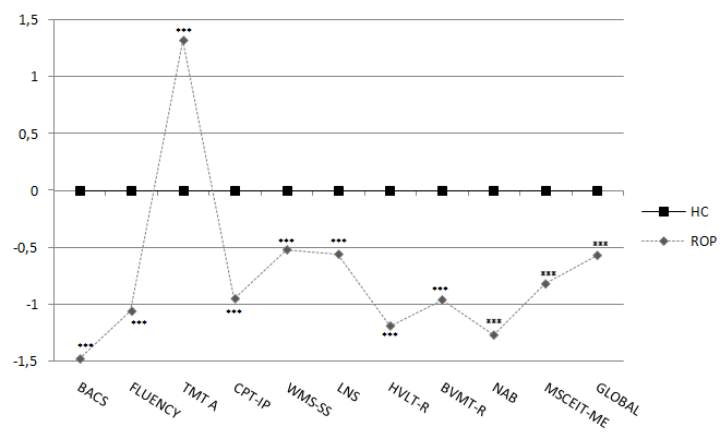

Figure 1: Differences in cognitive Profile between ROP and $\mathrm{HC}$, Standardized scores: $\mathrm{HC}$ mean $=\mathrm{O}, \mathrm{SD}=1 ; \mathrm{t}=\mathrm{t}$ student test; ***Pvalue $<0.000$, Abbreviations: $\mathrm{ROP}=$ recent onset psychosis; $\mathrm{HC}=$ Healthy control; $\mathrm{TMT}^{-} \mathrm{A}$ : Trail Making Test Part A; BACS=the Brief Assessment of Cognition in Schizophrenia; Fluency= Category Fluency: Animal Naming; CPT-IP=Continuous Performance Test Identical Pairs; WMS-SS Wechsler Memory Scale-lll Spatial Span; LNS= Letter number span; HVLT'R= Hopkins Verbal Learning Test- Revised; BVMT-R Brief Visuospatial Memory Test ${ }^{\text {Revised; }} \mathrm{NAB}=$ Neuropsychological Assessment Battery (NAB); MSCEIT ME=Mayer-Salovey ${ }^{\circ}$ Caruso Emotional Intelligence Test, Managing Emotions subscale.

As a consequence, one of the most studied candidate genes for schizophrenia risk is the gene encoding the D2 dopamine receptor (DRD2). In this respect, the findings from the Schizophrenia Working Group of the Psychiatric Genomics Consortium have supported the association of DRD2 with schizophrenia [7]. Individual differences in $D R D 2$ expression may contribute to the risk of neuropsychiatric disorders such as schizophrenia and those differences may be related to the effect of the combination of environmental and genetic factors.

The ankyrin repeat and kinase domain containing -1'gene $(A N N K 1)$ is closely linked to the DRD2 gene on chromosome 11 . The single nucleotide polymorphism (SNP) rs1800497 C>T, also known as Taq1A, is located in exon 8 of the $A N N K 1$ gene and causes a non ${ }^{-}$conservative amino acid change (glu713Lys) [8]. This gene is a member of an extensive family of proteins involved in signal transduction pathways and the Taq1A, while unlikely to affect the structural integrity may affect substrate-binding [9]. In this respect, a recent meta ${ }^{-}$ analysis [10] of molecular imaging studies including healthy and clinical samples reported that rs1800497 strongly influenced the striatal D2 binding, so that the $\mathrm{T}^{-}$allele carriers $\left(\mathrm{T}^{+}\right)$showed a 30 to $40 \%$ reduction of striatal binding compared to the T-allele non carriers $\left(\mathrm{T}^{-}\right)[11,12]$. This SNP therefore, may alter the expression and function of the gene encoding $D R D 2$ due its proximity and ANKK1 has been described as a candidate gene for schizophrenia risk $[13,14]$.

The DAS plays a role in modulating cognitive processes [15]. DRD2and ANKK1 is expressed predominantly in striatum which is interconnected with numerous brain areas including dorsolateral prefrontal cortex, limbic cortex and hippocampus [16]. It is well known that this complex network is crucial to human cognition and particularly relevant to higher order cognitive functions such as executive function (EF) and working memory (WM) $[17,18]$. Evidence from healthy and clinical samples suggests a relationship between rs 1800497 allele status of the ANKK1 and cognitive function. The $\mathrm{T}$ allele has been linked to a lower mean general cognitive ability in general population [19] and difficulties in WM, EF and speed processing in healthy subjects [20-23]. Moreover, studies of trauma brain injury (TBI) have demonstrated that $\mathrm{T}^{+}$performed worse in WM tasks than $\mathrm{T}^{-}$after a TBI [24-26]. In addition to this, in the field of addiction research, the mutant allele has also been implicated in deficits in EF performance [27].

There is a large body of evidence indicating that cognitive deficits are enduring, persistent and stable core features of schizophrenia [28].These deficits are observable even before the onset of first psychotic symptoms, are closely related to functional outcome, persist when psychotic symptoms remit and do not respond accurately to current antipsychotic treatment $[29,30]$. It has been largely described a "global cognitive impairment " across a wide range of higher order cognitive domains such as speed processing, working memory, attention/vigilance, visual and verbal learning, executive functions and social cognition $[31,32]$. However, the heterogeneity of the wide range of cognitive tests used in assessing neuropsychological performance in schizophrenia have restricted comparison between studies and have hindered the development of treatment strategies targeting those deficits. In order to make the assessment more homogeneous, the National Institute of Mental Health's (NIMH) Measurement and Treatment Research to Improve Cognition in Schizophrenia (MATRICS) group developed the MATRICS Consensus Cognitive Battery (MCCB), which has been translated and validated across the world [33]. Given that both schizophrenia and cognition have heritability ranging between 70 to $90 \%$ and 24 to $55 \%$, respectively $[34,35]$, cognitive deficits might be valuable endophenotypes for genetic research. Consensus in cognitive assessment, therefore, may facilitate the study of cognitive domains as intermediate phenotypes in genetic studies [36]. 
In the search for associations of dopamine-related genes with cognitive domains, the Val158Met SNP of the catechol-O'methyltransferase (COMT) has received a major focus of attention [37]. Some DRD2 variants have been also associated with cognitive deficits in schizophrenia [38-43].

Thus, our aims were to determine whether there is an interaction between allele and disease status on cognitive function and to examine the impact of carrying the vulnerability allele on cognition in the psychosis group.

\section{Methods}

\section{Participants}

We selected 198 caucasian subjects with both complete neuropsychological assessment and blood specimen drawn for DNA analysis. Sample included 128 recent onset psychosis (ROP) (defined as onset of full psychotic symptoms within the last 12 months) and 70 healthy controls (HC). ROP were outpatients aged between 18 to 35 years attending the Early Psychosis Program (EIP) from University Hospital, Pere Mata Institute of Reus, Spain. Exclusion criteria were: psychosis induced by substances or other medical conditions, intellectual disability, severe head injury and not understanding or speaking Spanish fluently. HC included patient's friends and non'genetic relatives. HC status was established by screening for past or current history of psychiatric disorders. All participants gave written informed consent to participate in the study. The study was approved by Committee for Ethical Clinical Investigation of the Hospital Sant Joan of Reus.

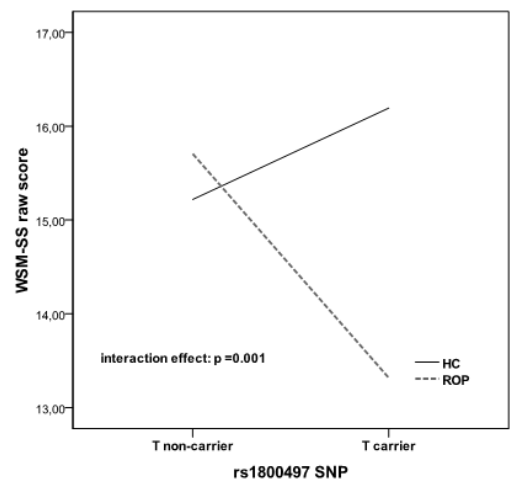

Figure 2: Group X allele status effect on WMS-SS. Adjusted for age, sex and years of education, Abbreviations: WMS-SS: Wechsler Memory Scale-III Spatial Span; HC: Healthy control; ROP= Recent onset psychosis.

\section{Procedures}

Clinical assessments: All assessments were administered on the same day or within two days at the same week by two experienced psychiatrists of the EIP team. Socio-demographic and clinical variables related to psychosis such as the duration of untreated psychosis and current pharmacological treatment were assessed by a direct interview. Each antipsychotic dose was transformed into chlorpromazine equivalents in $\mathrm{mg} /$ day [44]. Diagnosis of psychosis was confirmed by means of the Schedules for Clinical Assessment of Neuropsychiatry (SCAN) [45] following DSM-IV criteria (Diagnostic and Statistical Manual of Mental Disorders). The severity of psychotic symptoms was assessed by the Positive and Negative Symptom Scale (PANSS) [46] and severity of depressive symptoms by the Calgary Depression Scale (CDS) Level of functioning was assessed by The Global Assessment of Functioning (GAF) on a scale from 1 to 100 [47].
Cognitive assessment: Neuropsychological functioning was assessed by the MATRICS Consensus Cognitive Battery (MCCB) [33] administered by a single experienced psychologist. MCCB was administered when patients were clinically stable enough to undergo cognitive assessment. The MCCB contains 10 tests to measure cognitive performance grouped by 7 cognitive domains: i) Processing Speed was measured by the Trail Making Test Part A (TMT$A)$ : a test of visual scanning and visuomotor tracking; the Brief Assessment of Cognition in Schizophrenia (BACS)-symbol coding: a measure of visuomotor speed and Category Fluency: Animal Naming: a verbal index of speed of Processing; ii) Attention/Vigilance by the Continuous Performance Test-Identical Pairs (CPT-IP); iii) Working Memory by the Wechsler Memory Scale-III (WMS-III)- Spatial Span forward and backward (WMS-SS): a measure of nonverbal working memory in which respondent taps cubes in same (or reverse) sequence as test 
administrator asks and Letter number span (LNS): a measure of verbal working memory in which respondent mentally reorders strings of number and letters and repeats them to administrator; iv) Verbal Learning by the Hopkins Verbal Learning Test- Revised (HVLT-R): a list of 12 words presented 3 times, which must be recalled from memory; v)Visual Learning by the Brief Visuospatial Memory Test-Revised (BVMT-R): a test in which the participant is required to draw 6 geometrical figures as accurately as possible from memory; vi) Reasoning and Problem solving by the Neuropsychological Assessment Battery (NAB)
Mazes: seven timed paper-and'pencil mazes of increasing difficulty that measure foresight and planning and vii) Social cognition by the Mayer -Salovey-Caruso Emotional Intelligence Test, Managing Emotions subscale (MSCEITME): this test measures how well people solve emotional problems. Higher scores represent better performance with the exception of TMT $^{-}$A which score is reversed, thus high values indicated worse performance. A total score was obtained by averaging the raw scores of all tests transformed into $\mathrm{z}^{-}$scores.

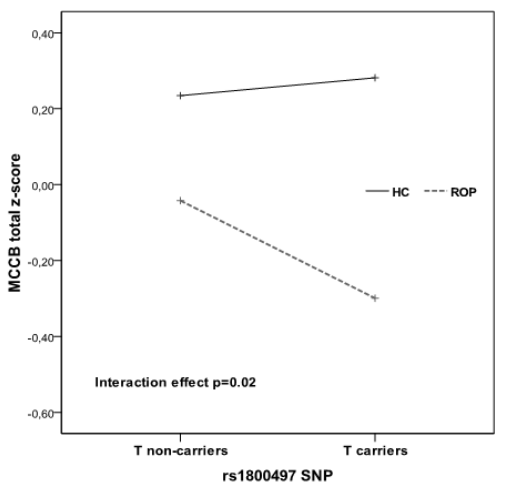

Figure 3: Group x a llele status on MCCB total score. Adjusted for age, sex and years of education, Abbreviations: MCCB: MATRICS Consensus Cognitive Battery; ROP: recent onset psychosis; HC: healthy control.

Finally, premorbid intellectual quotient (IQ) was estimated by the vocabulary subtest of the Wechsler Adult Intelligence Scale-III (WAIS-III).

DNA processing and genotyping: Total DNA was obtained from the peripheral blood, isolated using the Gentra ${ }^{\text {fi }}$ PureGene reagents (Qiagen, Barcelona, Spain). The rs1800497 variant was genotyped by the SequenomiPlex ${ }^{\text {fi }}$ MassARRAY platform, according to manufacturer's instructions (Sequenom, San Diego, CA). All assays included negative controls and a trio of Coriell samples (Na10830, Na10831 and $\mathrm{Na12147)}$ for quality control. The obtained genotyping rate for the rs 1800497 was $97.25 \%$.

\section{Statistical analysis}

Demographic, genetic and cognitive data between groups were tested with t student test or U-Mann Whitney test for quantitative variables and chi $^{-}$ square test or Fisher's exact test for categorical variables. Raw'scores of neuropsychological tests were transformed into standard scores ( $\mathrm{z}^{-}$scores) based on data of the HC group. For each neuropsychological test an analysis of covariance (ANCOVA) was further conducted. Based on previous findings discussed above, genotypes were grouped into two groups, that is, those with any $\mathrm{T}$ allele or $\mathrm{T}^{+}$(including TT and TC genotypes) and those with homozygote $\mathrm{CC}$ genotype or $\mathrm{T}^{-}$. Both the allelic $\left(\mathrm{T}^{+}\right.$and $\left.\mathrm{T}^{-}\right)$and disease status (ROP and $\mathrm{HC}$ ) and their interaction term were included as factors and age, sex and years of education as covariates. The interaction model examined whether differences in cognitive domains between ROP and HC differ as a function of allele status. Significant main effects of genetics of interaction effects were further explored separately in ROP and HC. 


\begin{tabular}{|c|c|c|c|c|}
\hline & $\begin{array}{c}\mathrm{HC} \\
(\mathrm{N}=70)\end{array}$ & $\begin{array}{c}\text { ROP } \\
(\mathrm{N}=128)\end{array}$ & $\begin{array}{c}\text { Statistic } \\
t X^{2}\end{array}$ & $\mathrm{p}$ \\
\hline \multicolumn{5}{|c|}{ Socio-demographic variables } \\
\hline Age, years (mean, SD) & $23.50(4.50)$ & $23.64(5.49)$ & 1.10 & .88 \\
\hline Sex, male (\% of male) & $36(51.4)$ & $84(65.6)$ & 3.82 & 0.05 \\
\hline Education years (median, $I Q R$ ) & $13(11-15)$ & $10(9-12)$ & $-5.22^{\circ}$ & $<.001$ \\
\hline \multicolumn{5}{|c|}{ Genetic variables } \\
\hline \multicolumn{5}{|l|}{ Allelic frequencies } \\
\hline & $23(32.9)$ & $44(34.4)$ & 0.47 & 0.88 \\
\hline & $47(66.7)$ & $84(65.6)$ & & \\
\hline \multicolumn{5}{|c|}{ Clinical variables } \\
\hline $\begin{array}{l}\text { DUP (days) (median, } I Q R \text { ) } \\
\text { PANSS (mean, } S D \text { ) }\end{array}$ & & $114(13-162)$ & & \\
\hline Positive & & $9.7(3.9)$ & & \\
\hline Negative & & $15.5(6.9)$ & & \\
\hline General & & $27.5(8.8)$ & & \\
\hline Total & & $52.8(16.7)$ & & \\
\hline GAF (mean, SD) & & $66.6(10.4)$ & & \\
\hline \multicolumn{5}{|c|}{ Antipsychotic treatment } \\
\hline CPZE $(\mathrm{mg} /$ day) (median, $I Q R)$ & & $383.4(200-513)$ & & \\
\hline \multicolumn{5}{|c|}{$\begin{array}{l}\text { Abbreviations: }[\mathrm{HC}=\text { healthy control; } \mathrm{ROP}=\text { recent onset } \mathrm{psychosis} ; \mathrm{T}+=\text { carriers of } \mathrm{T} \text { allele; } \mathrm{T}=\text { =non carriers of } \mathrm{T} \\
\text { allele; } \mathrm{SD}=\text { standard deviation; } \mathrm{IQR}=\text { interquartile range; } \mathrm{DUP}=\text { duration of untreated psychosis; } \\
\text { PANSS=Positive and Negative Symptom Scale; } \mathrm{GAF}=\text { global assessment functioning scale ;CPZE= } \\
\text { chlorpromazine equivalents; } \mathrm{t}=\mathrm{t} \text { student test } ; \mathrm{X} 2=\text { chi-Squared test ; }{ }^{*} \mathrm{U} \text { - Mann Whitney test }\end{array}$} \\
\hline
\end{tabular}

Table 1: Socio-demographical and clinical characteristics of participants.

Further, the impact of allele status on cognitive data among the clinical group was explored. Differences in cognitive tests between carriers $\left(\mathrm{ROP}^{-} \mathrm{T}^{+}\right)$and non ${ }^{-}$carriers $\left(\mathrm{ROP}^{-} \mathrm{T}^{-}\right)$were explored using ANCOVA's controlling for clinical variables on which they differed ( $\mathrm{p}$ value $<0.10)$.

Bonferroni correction for multiple comparisons was applied and the significance threshold was set at $\mathrm{p}<0.005$ (corrected for 10 tests included in MCCB) . All analyses were conducted using IBM SPSS Statistics for Windows (version 18).

\section{Results}

\section{Characteristics of participants}

As it can be seen in Table 1, groups differed in years of education and sex distribution. There was a higher proportion of males in the ROP group and lesser years of education. The genotype data of groups and whole sample was consistent with those expected from Hardy-Weinberg equilibrium $(\mathrm{X} 2=0.68 ; \mathrm{p}=0.40)$. Frequency of $\mathrm{T}^{+}$was not significantly different between ROP and HC (X2 $=0.22 ; \mathrm{p}=0.88$ ).

\section{Effect of group and allelic status on cognition performance}

ROP patients showed significant impairment relative to $\mathrm{HC}$ on each of the 10 cognitive tests of the MCCB battery and in the total score (all p values <0.001) (see Figure 1). As it is shown in Table 2, we did not find significant effects of diagnosis or genetics on premorbid IQ. However, a significant main effect of group was found in tests encompassing all cognitive domains with the exception of working memory domain that not survived to Bonferroni correction. We did not find a significant a main effect of genetics on cognitive performance, however there was a significant interaction effect between disease and genetics on WMS -SS $\quad(\mathrm{F}=10.32, \quad \mathrm{p}=0.002$, partial eta squared $=0.05)$ and on MCCB total score $(F=5.02$, $\mathrm{p}=0.02$, partial eta squared $=0.03$ ) ( see figures 2 and 3$)$.

To determine the nature of this interaction, differences in WMS-SS and MCCB total performance were further explored stratifying the sample by allele and disease status. $\mathrm{ROP}^{-} \mathrm{T}^{+}$ performed worse in WMS-SS than $\mathrm{HC}^{-} \mathrm{T}^{+}(\mathrm{t}=4.70$, $\mathrm{p}<0.000)$ while that difference was not found among $\mathrm{T}^{-}(\mathrm{t}=0.95, \mathrm{p}=0.34)$. With regards $\mathrm{MCCB}$ total score, both ROP $\mathrm{T}^{+}$and $\mathrm{T}^{-}$performed poorly than $\mathrm{HC}^{-} \mathrm{T}^{+} \quad(\mathrm{t}=6.53, \mathrm{p}<0.001)$ and $\mathrm{HC}^{-} \mathrm{T}^{-}$ $(t=4.99, p<0.001)$, respectively. When sample was stratified by disease status WSM-III and MCCB total scores were lower in $\mathrm{ROP}^{-} \mathrm{T}^{+}$compared to $\mathrm{ROP}^{-} \mathrm{T}^{-}$(table 3) while that difference was not found between $\mathrm{HC}^{-} \mathrm{T}^{+}$and $\mathrm{HC}^{-} \mathrm{T}^{-}$. In addition, the entire cognitive profile did not differ in $\mathrm{HC}$ as 
a function of allele status (table 1 supplementary material).

\section{Cognitive differences between ROP-T+ and ROP-T}

As we can see in table 3 , ROP- ${ }^{+}$performed significantly worse in MCCB total score, BACS, WMS-SS, LNS and HVLT tests, however only total MCCB and WMS-SS scores remained significantly lower after applying a Bonferroni correction $(\mathrm{p}=0.005)$.

In order to investigate whether differences in WMS-SS and MCCB total scores between carriers and non carriers were influenced by other demographic or clinical variables, differences with a $\mathrm{p}$ value $<0.10$ were included as covariates. $\mathrm{ROP}^{-}$ $\mathrm{T}^{+}$were more frequently male and tended to be more frequently treated with higher doses of antipsychotics. In addition, $\mathrm{ROP}^{-} \mathrm{T}^{+}$presented higher scores in the general and negative subscales of the PANSS and in the total PANSS score. Because of the skewed nature of chlorpromazine equivalent dose, it was logarithmically transformed to normalize it for the analysis. Correlation analysis between potential covariates revealed a strong positive significant correlationbetween PANSS negative and general subscales $(r=0.62, p<000)$. To avoid intercorrelation between covariates we decided to include the one with the lower $\mathrm{p}$ value. After controlling for sex, chlorpromazine equivalent dose, and PANSS negative subscale, ANCOVAs showed that WMS-SS $(\mathrm{F}=9.53$, $\mathrm{p}=0.003$, partial eta squared $=0.09)$ and $\mathrm{MCCB}$ total $(\mathrm{F}=7.09, \mathrm{p}=0.009$, partial eta squared $=0.08)$ remained significantly lower in those carrying the $\mathrm{T}$ allele.

\section{Discussion}

This study aimed to examine whether carrying the vulnerability $T$ allele has an impact on cognition measured by the MCCB in psychotic patients. Advances in molecular genetics have given a valuable push to increase the understanding of the etiopathogenic bases of complex psychiatric disorders. However, there is still a long way to go in the characterization of more homogeneous clinical phenotypes. In that sense, the study of patients at the early stages of psychosis can minimize the impact of the burden of a chronic disease and long-term antipsychotic treatment. Despite the relatively small sample size, the results that will be discussed below were obtained from a sample of young psychotic out patients recruited from the same catchment area, assessed using standardized consensual cognitive battery by the same specialized evaluator.

As expected, the cognitive profile of ROP patients was significantly more impaired than $\mathrm{HC}$, which is highly consistent with the extensive data available [31]. The special interest was to investigate the effect of the Taq1A T allele on cognitive differences found between groups. This is the first study to report that the impairment in non'verbal working memory is influenced by vulnerability allele. Our main finding therefore, is that ROP $\mathrm{T}^{+}$perform worse than $\mathrm{HC} \mathrm{T}^{+}$in non verbal working memory while that difference was not found between ROP and $\mathrm{HC}$ not carrying the $\mathrm{T}$ allele. Nor a main effect of genetics neither an interaction effect with diagnosis was found on the rest of cognitive tests. Our results are in contrast with a previous Spanish study [42] which failed to find differences in cognitive performance between $\mathrm{T}^{+}$and $\mathrm{T}^{-}$in their firstepisode sample composed by 84 adolescents and $85 \mathrm{HC}$. In that study, different cognitive tests were used to measure cognitive performance and authors suggest that negative findings may in part be due to the incomplete maturation of brain areas controlling high'order cognitive functions. More recently, Nkam and collegues [43], performed a similar study including 52 subjects with established schizophrenia and $53 \mathrm{HC}$. They did not find a significant disease-allele interaction on their cognitive outcome variables related to executive function and attention but they reported a disease interaction with rs6275 variant of $D R D 2$ gene on Stroop test performance. The three tests included differed with those in the MCCB measuring the same domains. Again, differences in sample characteristics and in tests assessing cognition limit comparison with our findings. 


\begin{tabular}{|c|c|c|c|c|}
\hline & $\begin{array}{c}\mathrm{HC} \\
(\mathrm{N}=70)\end{array}$ & $\begin{array}{c}\text { ROP } \\
(\mathrm{N}=128)\end{array}$ & $\begin{array}{c}\text { Statistic } \\
\mathrm{t} \mathrm{X}^{2}\end{array}$ & $\mathrm{p}$ \\
\hline \multicolumn{5}{|c|}{ Socio-demographic variables } \\
\hline Age, years (mean, SD) & $23.50(4.50)$ & $23.64(5.49)$ & 1.10 & .88 \\
\hline Sex, male ( $\%$ of male) & $36(51.4)$ & $84(65.6)$ & 3.82 & 0.05 \\
\hline Education years (median, $I Q R$ ) & $13(11-15)$ & $10(9-12)$ & $-5.22^{\circ}$ & $<.001$ \\
\hline \multicolumn{5}{|c|}{ Genetic variables } \\
\hline \multicolumn{5}{|l|}{ Allelic frequencies } \\
\hline $\mathrm{T}^{+}$ & $23(32.9)$ & $44(34.4)$ & 0.47 & 0.88 \\
\hline $\mathrm{T}^{-}$ & $47(66.7)$ & $84(65.6)$ & & \\
\hline \multicolumn{5}{|c|}{ Clinical variables } \\
\hline $\begin{array}{c}\text { DUP (days) (median, } I Q R \text { ) } \\
\text { PANSS (mean, } S D)\end{array}$ & & $114(13-162)$ & & \\
\hline Positive & & $9.7(3.9)$ & & \\
\hline Negative & & $15.5(6.9)$ & & \\
\hline General & & $27.5(8.8)$ & & \\
\hline Total & & $52.8(16.7)$ & & \\
\hline $\mathrm{GAF}($ mean, $S D)$ & & $66.6(10.4)$ & & \\
\hline \multicolumn{5}{|c|}{ Antipsychotic treatment } \\
\hline CPZE (mg/day) (median, $I Q R$ ) & & $383.4(200-513)$ & & \\
\hline \multicolumn{5}{|c|}{$\begin{array}{l}\text { Abbreviations: } \mathrm{HC}=\text { healthy control; } \mathrm{ROP}=\text { recent onset psychosis; } \mathrm{T}+=\text { carriers of } \mathrm{T} \text { allele; } \mathrm{T}-=\text { non carriers of } \mathrm{T} \\
\text { allele; } \mathrm{SD}=\text { standard deviation; } \mathrm{IQR}=\text { interquartile range; } \mathrm{DUP}=\text { duration of untreated psychosis } \\
\text { PANSS=Positive and Negative Symptom Scale; } \mathrm{GAF}=\text { global assessment functioning scale } ; \mathrm{CPZE}= \\
\text { chlorpromazine equivalents; } \mathrm{t}=\mathrm{t} \text { student test } ; \mathrm{X} 2=\text { chi-Squared test } ;{ }^{*} \mathrm{U} \text {-Mann Whitney test }\end{array}$} \\
\hline
\end{tabular}

Table 2: Effect of allele and group status on cognition.

When analysis was carried out stratifying by diagnosis, we found a global cognitive impairment in $\mathrm{ROP}^{-} \mathrm{T}^{+}$compared with $\mathrm{ROP}^{-} \mathrm{T}^{-}$whereas among controls, performance of carriers and non carriers was similar. More specifically, $\mathrm{ROP}^{-} \mathrm{T}^{+}$performed worse in speed processing, working memory and verbal learning domains and nearly significant in executive function and visual learning. However, when Bonferroni correction was applied only non verbal working memory continued to be significant at a more restrictive significant level. In addition, it continued to be more impaired after controlling for clinical confounders. This relationship between the vulnerability allele and poorer visual working memory performance has been previously reported in healthy samples [38]. In addition a previous study in subjects at high -risk of psychosis [41] reported an association of the vulnerability $\mathrm{T}$ allele with poorer performance in the psychomotor cognitive factor, which included a measure of WM. Moreover, deficits in memory and motor speed have been associated with $\mathrm{T}$ allele in healthy subjects [19]. Regarding verbal learning, positive associations with the vulnerability allele have been reported in trauma brain injured patients [26]. Unexpectedly, we only found a trend of association with EF. This is in contrast with findings from the field of addiction disorders and obesity in which the role ANKK1 gene in EF performance has been studied in more detail [27],[48]. One possible explanation is that EF in the MCCB is assessed by a single test. The $\mathrm{NAB}^{-}$mazes subtest measures foresight and planning while positive associations with T allele involved inhibitory control tasks [19], [23],[49]. Given that this study this was not specifically designed to investigate in depth the different components of executive function, the impact of rs1800497 SNP on other components of $\mathrm{EF}$ in psychosis needs further investigation [50].

Globally, our results suggest that prefrontal cognitive tasks are those which seem to be more influenced by TaqIA ANKK1. In schizophrenia research field, there is converging evidence that prefrontal dysfunction may underlie some aspects of cognitive impairment [51]. Considering that dopaminergic projections from the striatum connect to prefrontal cortex and that optimal dopaminergic activity is crucial to prefrontal cognitive processes [15],[52], it is plausible to assume a role of genes modulating the efficiency of dopamine receptors in those processes. However, the specific mechanism underlying this association remains unknown. Despite strong evidence from molecular neuroimaging studies about the influence of the TaqIA in D2 receptor binding, a direct causal effect has not been demonstrated yet [10]. Furthermore, it is also possible that other variants in linkage disequilibrium with rs1800497 may affect the DR2 function. In fact, the Taq1A variant itself was previously thought to be located 
within the $D R D 2$ gene. It has also been suggested, that $A N N K 1$ gene, together with $D R D 2$, NCAM1 and TTC12 genes might form the named NTAD region on Chr11q22-23. This region may work as a functional unit and may confer a "general vulnerability" risk yielding distinct results depending on the combination of other genes and environmental factors [53], [54].

\section{Limitations}

The main limitation of the study is the relative small sample size that lacked power to detect some associations and prevented us to perform a genotypic approach instead of allelic approach. However, the allelic approach has been proved to be useful previously [55]. Taking into account the few studies available in psychosis, our findings might be considered preliminary and need replication. Apart from the main limitation regarding the sample size, some other shortcomings have to be considered. Cognitive performance might be influenced by other variables that cannot be controlled for in our study. Moreover, the cross sectional nature of the study does not allow us to infer causality. Our findings cannot be generalized to other populations including patients with longer antipsychotic treatment and longer illness duration. Importantly, one single SNP within the ANKK1 was included, thus the involvement of other polymorphisms or interactions with other genetic variants cannot be discarded. It has also to be considered the small effect size of the associations found. This is in line with the nature of genetic studies in which molecular changes individually produce a small effect on the clinical phenotype. Complex neuropsychiatric disorders are polygenic in nature with each gene contributing a modest increase to liability.

\section{Conclusion}

Despite these limitations, our study provides preliminary evidence for the potential role of the rs1800497 SNP of the ANNK1 gene in modulating cognitive performance in recently diagnosed psychotic patients. Considering that cognitive dysfunction is one of the core symptoms of schizophrenia causing disability and poor outcome, advances in the investigation of the factors influencing worse cognitive outcomes are needed in order to advance in the search of new therapeutic target conditions. Moreover, the focus on well-defined cognitive domains is in line with the perspective of NIMH research domain criteria initiative which conceptualization was in turn influenced by the MATRICS proposal [56]. The use of MCCB battery in measuring cognitive performance may therefore facilitate comparison with future studies. Future studies including a large number of psychotic patients are warranted to further investigate the effect of the vulnerability $T$ allele on specific components of cognitive domains. In addition, the role of a single or double dose of $\mathrm{T}$ allele needs also to be studied in larger samples. 


\begin{tabular}{|c|c|c|c|c|}
\hline & $\begin{array}{l}\text { ROP- T } \\
(\mathrm{N}=84)\end{array}$ & $\begin{array}{l}\text { ROP-T }^{+} \\
(\mathrm{N}=44)\end{array}$ & Statistic $\left(\mathrm{t}, \mathrm{X}^{2}\right.$ & $\mathrm{p}$ \\
\hline \multicolumn{5}{|l|}{ Sociodemographic variables } \\
\hline Age, years (mean, SD) & $23.95(5.73)$ & $23.06(5.01)$ & 0.86 & 0.38 \\
\hline Sex, male (\% of male) & $49(58.3)$ & $35(79.5)$ & 4.85 & 0.02 \\
\hline Education years (median, IQR) & $10(9-13)$ & $10(9-12)$ & $-1.06^{*}$ & 0.28 \\
\hline \multicolumn{5}{|l|}{ Clinical variables } \\
\hline DUP (days) (median, IQR) & $\begin{array}{l}58.50 \\
(12.50-149.50)\end{array}$ & $\begin{array}{l}60.5 \\
(13.25-188.50)\end{array}$ & $-0.58 *$ & 0.56 \\
\hline \multicolumn{5}{|l|}{ PANSS (mean, SD) } \\
\hline Positive & $9.71(3.97)$ & $9.86(4.00)$ & -0.20 & 0.84 \\
\hline Negative & $14.33(5.93)$ & $17.79(7.95)$ & -2.66 & 0.008 \\
\hline General & $26.07(7.82)$ & $29.98(9.97)$ & -2.20 & 0.03 \\
\hline Total & $50.08(14.45)$ & $57.62(19.27)$ & -2.22 & 0.03 \\
\hline CDS (median, IQR) & $1(0-5)$ & $1(0-10)$ & $-1.01 *$ & 0.31 \\
\hline $\mathrm{GAF}($ median, $I Q R)$ & $65(60-50)$ & $60(60-70)$ & $-0.77^{*}$ & 0.47 \\
\hline \multicolumn{5}{|l|}{ Antipsychotic treatment } \\
\hline CPZE (median, IQR) & $300(100-450)$ & $424(225-600)$ & $-1.78 *$ & 0.07 \\
\hline \multicolumn{5}{|l|}{ Cognitive variables (mean, SD) } \\
\hline Premorbid IQ(standard score) & $98.86(14.66)$ & $96.19(18.36)$ & 0.63 & 0.52 \\
\hline \multicolumn{5}{|l|}{$M C C B$ (raw-scores) } \\
\hline BACS & $47.90(12.08)$ & $43.00(16.08)$ & 1.94 & 0.05 \\
\hline Fluency & $18.93(5.62)$ & $17.13(4.97)$ & 1.78 & 0.07 \\
\hline TMT-A(median, $I Q R)$ & $34(26-41)$ & $39(28-52)$ & $-1.38^{*}$ & 0.16 \\
\hline \multicolumn{5}{|l|}{ Attention and vigilance } \\
\hline CPT-IP & $2.13(0.60)$ & $1.97(0.82)$ & 1.12 & 0.26 \\
\hline \multicolumn{5}{|l|}{ Working memory } \\
\hline WMS-SS & $15.34(3.64)$ & $12.95(4.12)$ & 3.37 & 0.001 \\
\hline LNS & $12.86(2.67)$ & $11.25(3.64)$ & 2.41 & 0.01 \\
\hline \multicolumn{5}{|l|}{ Verbal learning } \\
\hline HVLT-R & $23.34(5.71)$ & $21.04(3.98)$ & 2.65 & 0.009 \\
\hline \multicolumn{5}{|l|}{ Visual learning } \\
\hline BVMT-R & $22.81(7.64)$ & $20.09(7.81)$ & 1.87 & 0.06 \\
\hline \multicolumn{5}{|l|}{ Rea soning and problem solving } \\
\hline $\mathrm{NAB}$ & $18.44(5.90)$ & $16.30(6.37)$ & 1.88 & 0.07 \\
\hline Social cognition & $86.63(9.76)$ & $84.36(11.35)$ & 1.31 & 0.26 \\
\hline $\begin{array}{l}\text { MSCEIT-ME } \\
\text { MCCB total score }(z \text {-score })\end{array}$ & $-0.09(0.46)$ & $-0.39(0.56)$ & 2.89 & 0.005 \\
\hline
\end{tabular}

Table 3: Characteristics T carriers and T non-carriers among ROP. Abbreviations: ROP $=$ recent onset psychosis; $H C=H e a l t h y$ control; $\mathrm{T}+=$ carriers of $\mathrm{T}$ allele; $\mathrm{T}$ - : non-carriers of the Tallele; DUP=duration of untreated psychosis; PANSS=Positive and Negative Symptom Scale; $C D S=$ Calgary depression scale; GAF= global assessment functioning scale ;CPZE=estimated equivalent amount of chlorpromazine; $\mathrm{IQ}=$ intelligence quotient; $\mathrm{MCCB}=$ MATRICS Consensus Cognitive Battery; TMT-A: Trail Making Test Part A ; BACS=the Brief Assessment of Cognition in Schizophrenia ; Fluency= CategoryFluency: Animal Naming;CPT-IP=Continuous Performance Test-Identical Pairs; WMS-SS Wechsler Memory Scale-III Spatial Span; LNS= Letter number span ; HVLT-R= Hopkins Verbal Learning Test- Revised; BVMT-R Brief Visuospatial MemoryTest -Revised;NAB=Neuropsychological Assessment Battery (NAB);MSCEIT-ME=Mayer-Salovey-Caruso Emotional Intelligence Test, Managing Emotions subscale. X2 = chi-Squared; $\mathrm{t}=\mathrm{t}$ student test; * U- Mann Whitneytest; $\mathrm{SD}=\mathrm{standard}$ deviation; $\mathrm{IQR}=$ interquartile range

\section{Acknowledgments}

The authors would like to acknowledge the technicians from the Biobanc-IISPV in Reus (http://www.iispv.cat) for sample management and CEGEN-PRB2-ISCIII for the genotyping service.

This work was supported by the Spanish Ministry of Health, Instituto de Salud Carlos III ISCIIISGEFI and European Regional Development Fund (ERDF) (grant number PT13/0001).
Funding: Spanish Ministry of Health, Instituto de Salud Carlos III ISCIII-SGEFI and European Regional Development Fund (ERDF) (grant number PT13/0001).

\section{References}

1. Seeman $P$, Lee $T$, Chau-Wong $M$, et al. Antipsychotic drug doses and neuroleptic/dopamine receptors. Nature 261(5562), 717-719 (1976). 
2. Perez SM, Lodge DJ. Aberrant dopamine D2-like receptor function in a rodent model of schizophrenia. J. Pharmacol. Exp. Ther 343(2), 288-295 (2012).

3. Knable MB, Egan MF, Heinz A, et al. Altered dopaminergic function and negative symptoms in drug-free patients with schizophrenia. [123I]iodobenzamide SPECT study. Br. J. Psychiatry 171(1), 574-577 (1997).

4. Heinz A, Schlagenhauf F. Dopaminergic dysfunction in schizophrenia: salience attribution revisited. Schizophr. Bull 36(3), 472-485 (2010).

5. Howes OD, Kapur S. The Dopamine Hypothesis of Schizophrenia区: Version III-The Final Common Pathway. Schizophr. Bull 35(3), 549-562 (2009).

6. Edwards AC, Bacanu SA, Bigdeli TB, et al. Evaluating the dopamine hypothesis of schizophrenia in a largescale genome-wide association study. Schizophr. Res 176(2-3), 136-140 (2016).

7. Schizophrenia Working Group of the Psychiatric Genomics Consorcium. Biological insights from 108 schizophrenia-associated genetic loci. Nature 511(7510), 421-427, (2014).

8. Neville MJ, Johnstone EC, Walton RT. Identification and characterization of ANKK1: A novel kinase gene closely linked to DRD2 on chromosome band 11q23.1. Hum. Mutat 23(6), 540-545 (2004).

9. Ghosh J, Pradhan S, Mittal B. Identification of a novel ANKK1 and other dopaminergic (DRD2 and DBH) gene variants in migraine susceptibility. Neuro. Mol. Med 15(1), 61-73 (2013).

10. Gluskin BS, Mickey BJ. Genetic variation and dopamine D2 receptor availability凶: a systematic review and meta-analysis of human in vivo molecular imaging studies. Transl. Psychiatry 6(3), e747-8 (2016).

11. Eisenstein SA, Bogdan R, Love-Gregory $L$, et al. Prediction of striatal D2 receptor binding by DRD2/ ANKK1 TaqIA allele status. Synapse 70(10), 418-431 (2016)

12. Ritchie $T$, Noble EP. Association of seven polymorphisms of the D2 dopamine receptor gene with brain receptor-binding characteristics. Neurochem. Res 28(1), 73-82 (2003).

13. Ponce $G$, Pérez-González $R$, Aragüés $M$, et al. The ANKK1 kinase gene and psychiatric disorders. Neurotox. Res 16(1), 50-59 (2009).

14. Gonzalez-Castro TB, Hernández-Díaz Y, Juárez-Rojop $\mathrm{IE}$, et al. The role of C957T, Taql and Ser311Cys polymorphisms of the DRD2 gene in schizophrenia: systematic review and meta-analysis. Behav. Brain. Funct 12(1), 29 (2016).

15. Reuter M, Peters K, Schroeter K, et al. The influence of the dopaminergic system on cognitive functioning: $A$ molecular genetic approach. Behav. Brain. Res 164(1), 93-99 (2005)

16. Middleton FA and Strick PL. Basal ganglia output and cognition: evidence from anatomical, behavioral, and clinical studies. Brain. Cogn 42(2), 183-200 (2000).

17. Egerton A, Mehta MA, Montgomery AJ, et al. The dopaminergic basis of human behaviors: A review of molecular imaging studies. Neurosci. Biobehav. Rev 33(7), 1109-1132 (2009).

18. Marie RM, Defer GL. Working memory and dopamine: clinical and experimental clues. Curr. Opin. Neurol 16(2), 29-35 (2003).

19. Bolton JL, Marioni RE, Deary IJ, et al. Association between polymorphisms of the dopamine recepto D2 and catechol-o-methyl transferase genes and cognitive function. Behav. Genet 40(5), 630-638 (2010).

20. Markett S, Montag C, Walter NT, et al. On the molecular genetics of flexibility: the case of task- switching, inhibitory control and genetic variants. Cogn. Affect. Behav. Neurosci 11(4), 644-651 (2011).

21. Richter A, Guitart-Masip M2, Barman A, et al. Valenced action/inhibition learning in humans is modulated by a genetic variant linked to dopamine D2 receptor expression. Front. Syst. Neurosci 8(1), 140 (2014).

22. Stelzel C, Basten U, Montag C, et al. Effects of dopamine-related gene-gene interactions on working memory component processes. Eur. J. Neurosci 29(5), 1056-1063 (2009).

23. Stelzel C, Basten U, Montag C, et al. Frontostriatal involvement in task switching depends on genetic differences in $\mathrm{d} 2$ receptor density. J. Neurosci 30(42), 14205-14212 (2010).

24. Yue JK, Pronger AM, Ferguson AR, et al. Association of a common genetic variant within ANKK1 with sixmonth cognitive performance after traumatic brain injury. Neurogenetics 16(3), 169-180 (2015).

25. Bales JW, Wagner $A K$, Kline $A E$, et al. Persistent

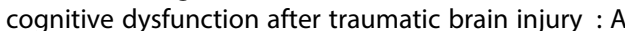
dopamine hypothesis. Neurosci. Biobehav. Rev 33(7), 981-1003 (2009).

26. McAllister TW, Rhodes $\mathrm{CH}$, Flashman LA, et al. Effect of the dopamine $\mathrm{D} 2$ receptor $\mathrm{T}$ allele on response latency after mild traumatic brain injury. Am. J. Psychiatry 162(9), 1749-1751 (2005).

27. Fagundo $A B$ et al. Dopamine DRD2/ANKK1 Taq1A and DAT1 VNTR polymorphisms are associated with a cognitive flexibility profile in pathological gamblers. J. Psychopharmacol 28(12), 1170-1177 (2014).

28. Green MF. Impact of cognitive and social cognitive impairment on functional outcomes in patients with schizophrenia. J. Clin. Psychiatry 77(2), 8-11 (2016).

29. Goldberg TE, Goldman RS, Burdick KE, et al. Cognitive improvement after treatment with secondgeneration antipsychotic medications in first-episode schizophrenia: is it a practice effect?. Arch. Gen. Psychiatry 64(10), 1115-1122 (2007).

30. Keefe RS, Silva SG, Perkins DO, et al. The effects of atypical antipsychotic drugs on neurocognitive impairment in schizophrenia: a review and metaanalysis. Schizophr. Bull 25(2), 201-222 (1999).

31. Schaefer J, Giangrande E, Weinberger DR, et al. The global cognitive impairment in schizophrenia: consistent over decades and around the world. Schizophr. Res 150(1), 42-50 (2013).

32. Nuechterlein $\mathrm{KH}$, Ventura J, Subotnik $\mathrm{KL}$, et al. The early longitudinal course of cognitive deficits in schizophrenia. J. Clin. Psychiatry 75(2)2, 25-29 (2014).

33. Nuechterlein $\mathrm{KH}$, Green MF, Kern RS, et al. The MATRICS Consensus Cognitive Battery, part 1: test selection, reliability, and validity. Am. J. Psychiatry 165(2), 203-213 (2008).

34. Greenwood TA, Light GA, Swerdlow NR, et al. Association analysis of 94 candidate genes and schizophrenia-related endophenotypes. PLoSOne 7(1), e29630 (2012).

35. Sabb FW, Bearden CE, Glahn DC, et al. A collaborative knowledge base for cognitive phenomics. Mol. Psychiatry 13(4), 350-360 (2008)

36. Gur RE, Calkins ME, Gur RC, et al. The Consortium on the Genetics of Schizophrenia: neurocognitive endophenotypes. Schizophr. Bull 33(1), 49-68 (2007).

37. Zai G, Robbins TW, Sahakian BJ, et al. A review of molecular genetic studies of neurocognitive deficits in schizophrenia. Neurosci. Biobehav. Rev 72(1), 50-67 (2017).

38. Xu H, Kellendonk CB, Simpson EH, et al. DRD2 C957T polymorphism interacts with the COMT Val158Met polymorphism in human working memory ability. Schizophr. Res 90(1-3), 104-107 (2007). 
39. Chien YL, Hwu HG, Fann CSJ, et al. DRD2 haplotype associated with negative symptoms and sustained attention deficits in Han Chinese with schizophrenia in Taiwan. J. Hum. Genet 58(4), 229-232 (2013).

40. Sakurai H, Bies RR, Stroup ST, et al. Dopamine D2 receptor occupancy and cognition in schizophrenia: analysis of the CATIE data. Schizophr. Bull 39(3), 564-574 (2013).

41. Ramsay $\mathrm{H}$, Barnett $\mathrm{JH}$, Miettunen J, et al. Association between Dopamine Receptor D2 (DRD2) Variations rs6277 and rs1800497 and Cognitive Performance According to Risk Type for Psychosis: A Nested Case Control Study in a Finnish Population Sample. PLoSOne 10(6), e0127602 (2015).

42. Bombin I, Arango C, Mayoral M, et al. DRD3, but not COMT or DRD2, genotype affects executive functions in healthy and first-episode psychosis adolescents. Am. J. Med. Genet. B. Neuropsychiatr. Genet 147(6), 873-879 (2008).

43. Nkam I, Ramoz N, Breton F, et al. Impact of DRD2/ ANKK1 and COMT Polymorphisms on Attention and Cognitive Functions in Schizophrenia. PLoSOne 12(1), e0170147 (2017)

44. Gardner DM, Murphy AL, O'Donnell $H$, et al. International consensus study of antipsychotic dosing. Am. J. Psychiatry 167(6), 686-693 (2010).

45. Wing JK, Babor T, Brugha T, et al. SCAN. Schedules for Clinical Assessment in Neuropsychiatry. Arch. Gen. Psychiatry 47(6), 589-593, (1990).

46. Peralta V, Cuesta MJ. Psychometric properties of the positive and negative syndrome scale (PANSS) in schizophrenia. Psychiatry. Res 53(1), 31-40 (1994).

47. Hall RC, Parks J. The modified global assessment of functioning scale: addendum. Psychosomatics 36(4), 416-417 (1995)

48. Ariza $M$, Garolera $M$, Jurado $M A$, et al. Dopamine genes (DRD2/ANKK1-TaqA1 and DRD4-7R) and executive function: their interaction with obesity. PLoSOne 7(7), e41482 (2012).

49. Jocham G, Klein TA, Neumann J, et al. Dopamine DRD2 polymorphism alters reversal learning and associated neural activity. J. Neurosci 29(12), 3695-3704 (2009).

50. Miyake A, Friedman NP. The Nature and Organisation

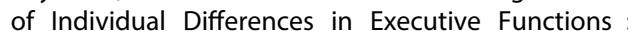
Four General Conclusions. Curr. Dir. Psychol. Sci 21(1), 8-14, (2012).

51. Lee J, Park S. Working memory impairments in schizophrenia: a meta-analysis. J. Abnorm. Psychol 114(4), 599-611 (2005).

52. Cropley VL, Fujita M, Innis RB, et al. Molecular imaging of the dopaminergic system and its association with human cognitive function. Biol. Psychiatry 59(10), 898-907 (2006)

53. Mota NR, Araujo-Jnr EV, Paixao-Cortes VR, et al. Linking dopamine neurotransmission and neurogenesis: The evolutionary history of the NTAD (NCAM1-TTC12-ANKK1-DRD2) gene cluster. Genet. Mol. Biol 35(4), 912-918, (2012).

54. Huang W, Payne TJ, Ma JZ, et al. Significant association of ANKK1 and detection of a functional polymorphism with nicotine dependence in an African-American sample. Neuropsychopharmacology 34(2), 319-330 (2009).

55. Noble EP. D2 dopamine receptor gene in psychiatric and neurologic disorders and its phenotypes. Am. J. Med. Genet. B. Neuropsychiatr. Genet 116(1), 103-125 (2003).

56. Schwarz E, Tost $H$, Meyer-Lindenberg A. Working memory genetics in schizophrenia and related disorders: An RDoC perspective. Am. J. Med. Genet. Part. B Neuropsychiatr. Genet 171(1), 121-131 (2015). 